\title{
TIVA versus Inhalational Agents for Pediatric Cardiac Intensive
}

\author{
Ramesh Chand Kashav ${ }^{1,2}$ ItiShri ${ }^{1,2}$ Jasvinder Kaur Kohli1,2 Rohan Magoon ${ }^{1,2}$ \\ ${ }^{1}$ Department of Cardiac Anaesthesia, Atal Bihari Vajpayee Institute \\ of Medical Sciences (ABVIMS), New Delhi, India \\ 2Dr. Ram Manohar Lohia Hospital, Baba Kharak Singh Marg, \\ New Delhi, India52134141

\begin{abstract}
Address for correspondence Dr. ItiShri, MD, Associate Professor, Department of Cardiac Anaesthesia, Atal Bihari Vajpayee Institute of Medical Sciences (ABVIMS) and Dr. Ram Manohar Lohia Hospital, Baba Kharak Singh Marg, New Delhi 110001, India
\end{abstract} \\ (e-mail: iti.anesthesia@gmail.com).
}

J Card Crit Care 2021;5:134-141.

\begin{abstract}
Keywords

- volatile agents

- intravenous agents

- pediatric critical care

- technology

The field of pediatric intensive care has come a long way, especially with the recognition that adequate sedation and analgesia form an imperative cornerstone of patient management. With various drugs available for the same, the debate continues as to which is the better: total intravenous anesthesia (TIVA) or inhalational agents. While each have their own advantages and disadvantages, in the present era of balance toward the IV agents, we should not forget the edge our volatile agents (VAs) might have in special scenarios. And ultimately as anesthesiologists, let us not forget that be it knob and dial, or syringe and plunger, our aim is to put pain to sleep and awaken a new faith to breathe.
\end{abstract}

\section{Introduction}

It became at once apparent to all the world that surgical anesthesia had become a reality and that pain was no longer the master but the servant of the body.

\section{J. Collins Warren 1921}

The modern-day anesthesia has indeed witnessed significant pharmacological, scientific and practical advances over the past 175 years, and the tenacity and enthusiasm with which the modern-day technology is being woven into the very texture of anaesthesia practice has brought us all a long way in our practice and implementation of the pharmacological and technological armamentarium for the ultimate benefit of our patients.

And appended to this armamentarium is the knowledge that our pediatric population is just not a little adult, and there are significant differences both physiologically and psychologically from that of an adult, and so a research and refinement in the technology, medicine, equipment, and training in the field of pediatric anesthesia is part of a process recording consistent progress.

Significant advancement has been made in pediatric cardiac surgery too, owing to major advances in pediatric cardiology, anesthesia, cardiopulmonary bypass (CPB) techniques, and perioperative cardiac intensive care. ${ }^{1-3}$

Volatile agents (VA) have been the cornerstone of pediatric anesthesia since 150 years. These agents satisfy the four pillars of anesthesia, that is, amnesia, analgesia, akinesia and sensory and autonomic blockade. ${ }^{4}$

With the discovery nitrous oxide by Priestly in 1772 and demonstration of ether anesthesia in 1846 at ether dome, our modern-day inhalational agents have come a long way.

The low solubility in blood facilitates rapid induction of anesthesiaalong withnonirritant, nonpungent, odorless, bronchodilatorandfewmetabolic sideeffectsproperties makesevoflurane an ideal anesthetic agent for induction in children. ${ }^{5-7}$ This spares both the patient as well as the anesthetist the pain, fear, and distress of an intravenous (IV) cannulation. Precise control of end-tidal anesthetic concentrations during published online Augurst 5, 2021
DOI https://doi.org/ $10.1055 / \mathrm{s}-0041-1732834$ ISSN 2457-0206 (c) 2021. Official Publication of The Simulation Society (TSS), accredited by International Society of Cardiovascular Ultrasound (ISCU).

This is an open access article published by Thieme under the terms of the Creative Commons Attribution-NonDerivative-NonCommercial-License, permitting copying and reproduction so long as the original work is given appropriate credit. Contents may not be used for commercial purposes, or adapted, remixed, transformed or built upon. (https://creativecommons.org/licenses/by-nc-nd/4.0/). Thieme Medical and Scientific Publishers Pvt. Ltd. A-12, 2nd Floor, Sector 2, Noida-201301 UP, India 
maintenance of anesthesia, and prompt recovery at the end of anesthesia independent of the duration of administration. Once the patient is deep asleep, one can switch to $100 \%$ oxygen for IV cannulation. The current ether anesthetics have limited cardiorespiratory depression and minimal risk for hepatorenal toxicity. These depress the circulation in a dose-dependent manner which is easily reversible by decreasing the anesthetic concentration. Spontaneous respiration is easy to maintain with VA; the decrease in tidal volume is offset by an increase in respiratory rate., ${ }^{4,9}$ Adverse events are rare and manageable. Mostly, if airway obstruction occurs, the anesthetist is at the advantageous head-end position to catch and control the airway immediately. Many anesthetists prefer to intubate patients once they are deeply anaesthetized with a VA alone ${ }^{10}$ Also, the easy availability of equipment of delivery, that is, vaporizers on the anesthesia workstation, require no extra energy for their operation and measurement of the depth of anesthesia by monitoring end-tidal concentrations (ETC), leading to a hassle-free use of VA with easy determination of the dose to attenuate adrenergic responses and awareness, sans any additional costs. With an ETC of 0.7 minimum alveolar concentration (MAC), awareness is extremely unlikely. ${ }^{11,12}$ Also, the responses at particular concentration are highly predictable and can be managed more effectively as compared to the IV agents that have high-interindividual variability. ${ }^{13}$ Although gaseous induction is considered to be associated with incidence of movement, cough, breath holding, laryngospasm, emergence agitation, nausea, and vomiting postoperatively, ${ }^{14-16}$ yet in a systematic review by Porter et al comparing the respiratory and hemodynamic perioperative adverse events in IV versus VA induction in pediatric anaesthesia revealed no significant differences between the two modalities. However, more adverse respiratory events were found with VA in children with respiratory illness. This, again, did not reach a level of significance. ${ }^{17}$ There are no significant concerns of drug tolerance or tachyphylaxis over a period of administration..$^{18}$

In a pediatric cardiac patient, induction anaesthetic technique is influenced by the original lesion and cardiac functional status. The anesthetic considerations for these patients differ considerably, depending on such factors as shunting, myocardial contractility, ventricular dilation or hypertrophy, outflow tract obstruction, dysrhythmias, and pulmonary hypertension. The selection of technique is based on the assessment of the potential risk and benefit in the individualized context, and clearly in these patients at a precarious balance of hemodynamics, the aim is to minimize even minor deviations in ventilation, pulmonary and systemic blood flow ratio (Qp/Qs ratio), arterial pressure control, and blood biochemistry. This includes knowledge about whether the patient is on parallel or single-ventricle physiology and relies deeply on relative resistance between systemic and pulmonary circulation. Isoflurane has been shown to better preserve contractility, heart rate (HR), and cardiac output (CO) in patients with congenital heart disease (CHD) and has become a common agent for maintenance of anesthesia in patients undergoing CHD surgery. Sevoflurane, with its ability to be used as an inhaled induction agent and its superiority over halothane in preserving $\mathrm{CO}$ and contractility, is an attractive choice. ${ }^{19-24}$ In a study by Rivenes et al, sevoflurane and isoflurane maintained $\mathrm{CO}$. Isoflurane was also noted to increase HR and lower systemic vascular resistance (SVR). Fentanyl and midazolam maintained myocardial contractility, but depressed $\mathrm{HR}$ and thus $\mathrm{CO}^{25}$

Left ventricular systolic function was mildly depressed by isoflurane and sevoflurane at 1.5 MAC and depressed by halothane at 1 and 1.5 MAC. Sevoflurane, halothane, isoflurane, or fentanyl/midazolam in 1 or $1.5 \mathrm{MAC}$ concentrations or their equivalent do not change $\mathrm{Qp}$ :Qs in patients with isolated atrial septal defect (ASD) or ventricular septal defect (VSD). ${ }^{26}$

Induction though is prolonged in patients with right to left shunts. However, in a study by Malhotra et al, in 35 patients presenting for Blalock-Taussig (BT) shunt, patients exposed to desflurane had shorter extubation times and length of ICU and hospital stay by nearly 3 days. Also, below 1 MAC, there was no tachycardia and airway irritation with desflurane. ${ }^{27}$ Similarly, myocardial performance index (MPI) showed that two commonly used anesthetic regimens, sevoflurane and fentanyl-midazolam, along with pancuronium, have no significant effect on myocardial function in infants with a functional single ventricle, as demonstrated by Ikemba et al..$^{28}$

But still, patients with poor cardiac function may not tolerate inhalational induction; hence, it is commonly used in low doses in combination with IV agents to produce the initial hypnosis.

Maintenance of anesthesia: Despite concerns of decreased cardiac contractility and SVR, hypoxic pulmonary vasoconstriction, VAs such as isoflurane (0.5-1.2\%) and sevoflurane have safe hemodynamic profiles. Although first used in 1974 on CPB, a recent resurgence in use of VAs on bypass is because of reports of anesthetic pre- and postconditioning, and hence cardioprotective properties, and a reduction in mortality in adult coronary bypass patients. ${ }^{29-34}$ Also, in patients undergoing coronary artery surgery with $\mathrm{CPB}$, the cardioprotective effects of sevoflurane were clinically most apparent when it was administered throughout the operation. ${ }^{35}$ Literature pertaining to such an effect in children, especially those with cyanotic CHD, is scarce and conflicting. ${ }^{36-38}$ In a study by Singh et al, preconditioning with isoflurane, sevoflurane, and desflurane was associated with significantly decreased postoperative release of CK-MB as compared to placebo group at 6 and 24 hours after admission to ICU. No significant differences were observed in the CK-MB levels among the three VAs. ${ }^{39}$

There are issues with administration, measurement of concentration at exhaust port, and problems of spillage, damaging plastic parts, occupational exposure and scavenging, and these are being tackled with a vigilant and futuristic approach, with a sound understanding of the pharmacokinetics and pharmacodynamics of $\mathrm{CPB}^{40,41}$.

Volatile Agents (VAs) In Pediatric ICU: Sedation depresses the patients' awareness of the environment as to prevent pain and anxiety, permit invasive procedures reduce stress, and improve compliance with mechanical ventilation. 
Undersedation increases the sympathetic stress response, while oversedation is associated with longer time on mechanical ventilation, prolonged stay in the intensive care unit, and increased brain dysfunction (delirium and coma). ${ }^{42,43}$

Sedation practices with the IV agents need a revision due to problems of hemodynamic instability, accumulation and affected metabolism due to reliance on adequate hepatic and renal function, tolerance, withdrawal reactions, and long-term consequences of neuropsychiatric disorders ${ }^{19,44}$; evidence is increasing that VAs are potential feasible alternatives to IV agents as sedative in ICU, associated with faster extubation times, and improved cardiovascular stability with no end-organ toxicity. ${ }^{19}$ An additional feature of muscle relaxation too is beneficial in adult respiratory distress syndrome (ARDS) cases. ${ }^{45,46}$

However, their use requires specialized delivery and scavenging system and rigorous staff training.

One of the first reported cases of sedation with isoflurane in ICU dates back to 1986 when Beirman et al<sup $>47$ utilized it in a case of refractory status asthamaticus unresponsive to usual IV sedative agents, followed by Kong et al, ${ }^{48}$ who compared isoflurane and midazolam for sedation and reported significant shorter extubation times and mean time to stopping sedation and writing home address with isoflurane.

These agents act on macroscopic, synaptic, and molecular levels. They decrease afferent noxious transmission at spinal cord level, while hypnosis and amnesia are mediated at supraspinal levels. They also inhibit excitatory presynaptic channel activity, which is mediated by neuronal nicotinic, serotonergic, and glutaminergic receptors, while also augmenting the inhibitory chloride current postsynaptic channel activity, which is mediated by GABAA and glycine receptors; inhibition at N-methyl-D-aspartate (NMDA) receptors by the anaesthetic gases are likely to be important mechanisms of action. ${ }^{10}$

Their use as an ICU sedative appears attractive, given they are simple to titrate, produce no active metabolites, and are predominantly cleared unchanged by pulmonary exhalation. They very selectively suppress consciousness but leave many autonomic functions intact. ${ }^{49}$ Volatile-based sedation demonstrates a reduction in time to extubation, with no increase in short-term adverse outcomes. In a comparative study between desflurane and propofol, Meiser et al found significantly shorter times to emergence, opening eyes, time to first response, extubation, recall of date of birth and five words with desflurane. There was also no adverse effect observed and cost benefits too were noted with desflurane as compared to propofol. ${ }^{50}$ As observed by Jerath et al, 141 patients who underwent coronary artery bypass grafting (CABG) were sedated using inhaled VA and displayed faster readiness to extubation time at 135 minutes (95-200 min) compared with those receiving IV propofol at 215 minutes (150-280 min) $(p<0.001)$. Extubation times were faster within the volatile group at 182 minutes (140-255 min) in comparison with propofol group at 291 minutes $(210-420 \mathrm{~min})(p<0.001)$. However, the volatile group showed a higher prevalence of vasodilatation, necessitating greater use of vasoconstrictors. There was no difference in postoperative pain scores, opioid consumption, sedation score, ICU or hospital length of stay, or patient mortality. ${ }^{51}$ Hellstrom et al, in their 100 patients randomized study following CABG, found median time from drug stop to extubation was shorter after sevoflurane compared to propofol sedation; 10 (10/100) minutes versus 25 $(21 / 240)$ minutes $(p<0.001)$. Time from extubation to adequate verbal response was shorter $(p=0.036)$. No differences were seen in ICU stay, adverse memories or recovery events occurred in this short-term sedation. ${ }^{52}$ Similarly, VA-based sedation offered better sedation profile, resulting in faster extubation time when compared to short-acting IV agent propofol. The study analyzed relatively short-term sedation after major surgical procedure (CABG). ${ }^{53,54}$

For long-term sedation, in a study by Tanigami et al, 40 patients undergoing mechanical ventilation after cardiovascular surgery receiving isoflurane (0.5-1.0 MAC) were well sedated without significant adverse effects such as renal, hepatic, or cardiovascular dysfunction. The highest serum inorganic fluoride concentration recorded was $45 \mathrm{mumol} / \mathrm{L}$ after 98 MAC h. Patients on isoflurane recovered more rapidly and were weaned from mechanical ventilation sooner than those sedated with IV drugs including fentanyl/midazolam. ${ }^{55}$ Similarly, in an analysis of 47 patients by Mesnil et al, long-term ( $>24$ hour) inhaled sevoflurane sedation seems to be a safe and effective alternative to IV propofol or midazolam. It decreases wakeup and extubation times (18.6 \pm 11.8 and $33.6 \pm 13.1 \mathrm{~min}$ ) in group sevoflurane than in group propofol $(91.3 \pm 35.2$ and $326.11 \pm 360.2 \mathrm{~min})$ or group midazolam (260.2 \pm 150.2 and $599.6 \pm 586.6 \mathrm{~min})$; and postextubation morphine consumption, and increases awakening quality. Mean plasma fluoride value was $82 \mu \mathrm{mol} / 1$ (range 12-220 $\mu \mathrm{mol} / \mathrm{l}$ ), and mean ambient sevoflurane concentration was $0.3 \pm 0.1$ ppm. $^{56}$

In a systematic review and meta-analysis by Kim et al, 13 trials with a total of 1027 patients were included. VA sedation administered through an AnaConDa (ACD), shortening the awakening time (mean difference [MD], 80.0 minutes; 95\% confidence intervals (95\% CIs), 134.5 to $25.6 ; p=$ 0.004] and extubation time (MD, 196.0 minutes; 95\% CIs, 305.2 to $86.8 ; p<0.001$ ) compared with IV sedation (midazolam or propofol). No differences in the lengths of ICU and hospital stay were noted between the two groups. Patients who received VA sedation showed lower serum troponin levels 6, 12 and 24 hours after ICU admission than patients who received IV sedation $(p<0.05) .{ }^{57}$

In a similar meta-analysis by Spence et al, in eight studies enrolling 610 patients, the times to extubation after ICU admission and sedation discontinuation were, respectively, 76 and 74 minutes less in patients who were sedated using VA. There was no difference in ICU or hospital length of stay. Patients who received VA sedation had troponin concentrations that were $0.71 \mathrm{ng} / \mathrm{mL}$ (95\% CI 0.23-1.2) lower than control patients. ${ }^{58}$ Jerath et al performed a meta-analysis, where reductions in extubation time were greater when comparing VA with midazolam, however, there was no significant difference in time to obey verbal commands, proportion of time spent in target sedation, adverse events, death, or length of hospital stay. ${ }^{59}$ 
After sedation with isoflurane, the in-hospital mortality and 365-day mortality were significantly lower than after propofol/midazolam sedation: 40 versus $63 \%(p=0.005)$ and 50 versus $70 \%(p=0.013)$, respectively. These observations as suggested could be rather the avoidance of deleterious side effects of IV sedatives. ${ }^{60}$

However, in few other studies, the data on mortality is equivocal in both in IV and VA groups. ${ }^{51,54,61}$

Studies in the pediatric patient are limited and restricted, mainly due to technical constraints of delivery of the agent but the results are encouraging. In a series by Palacios et al, in children with refractory bronchospasm, sevoflurane resulted in statistically significant decreases of $\mathrm{PaCO} 2$, and improvement in $\mathrm{pH}$ within 6 hours of administration. Only one patient presented hypotension responsive to volume administration at the beginning of the treatment. All patients could be extubated within a median time of 120 hours $^{62}$

Thirty-one patients, with a mean age of 9.5 years (range 0.4-23 years), were treated with isoflurane which led to improvement in $\mathrm{pH}$ and $\mathrm{p}(\mathrm{CO}(2))$ within 4 hours in this series of mechanically ventilated patients with life-threatening bronchospasm. The majority of patients in this series developed hypotension that was easily manageable. ${ }^{63}$ In a prospective study by Arnold et al, isoflurane could effectively provide sedation to pediatric patients (age 3 weeks to 19 years) for prolonged periods without significant adverse effects on cardiovascular, hepatic, or renal function. ${ }^{64}$ Similar other case reports and series are there in literature. $^{65-68}$

Rapid titratable effects, limited metabolism, and a reliable mode of administration make isoflurane an appealing alternative to the use of IV sedatives and narcotics in critically ill patients requiring prolonged mechanical ventilation. ${ }^{69}$

Another indication of use of VA in ICU is refractory status epilepticus both in adult and paediatric patients. ${ }^{70,71}$

In 23 patients with a median age of 6 months (50 percent of the patients had critical heart diseases), difficult to sedate with conventional agents, were treated with sevoflurane successfully with moderate hypotension and nonpurposeful movement as the only side effects observed..$^{72}$ In a difficult to sedate and wean 30-month-old burn female patient, Jung et al used sevoflurane via AnaConDa device successfully with minimal $\mathrm{CO}_{2}$ retention. ${ }^{73}$

In these unprecedented pandemic COVID-19 times, VAs prove to be a promising sedative alternative in ICU. With the flooding of ICUs with Corona positive patients and reported shortage of the IV medications along with positive plausible role of the VAs in the ARDS setting, Flinspach et al observed a reduced need for opioid sedation and an improved lung function with regard to the Pao2/Fio2 ratio and a successful resolution of multiple broncho-obstructive episodes by isoflurane in five patients with COVID-19 ARDS. ${ }^{74}$ With regard to the proven impact of underlying respiratory diseases and their attribution to a worse progression and outcome of COVID-19, volatile sedation could be beneficial in improving the COVID-19 associated lung injury. ${ }^{75,76}$

Rand et al in a retrospective analysis of patients receiving venovenous extracorporeal membrane oxygenation
(vv-ECMO) support and VA sedation in the surgical ICU showed that even with major impacts in lung mechanics and function, targeted sedation with VA is feasible and a dose-response relationship exists. ${ }^{77}$ Similarly, Laufenberg observed that the combination with VA sedatives make it possible to guide an ARDS patient to spontaneous breathing with only a short weaning period on vv-ECMO. ${ }^{78}$ Mieser et al observed in a case series of patients with severe ARDS on vv-ECMO, a reduced need for vasopressor therapy and improved lung function during isoflurane sedation. Opioid consumption could also be reduced. ${ }^{79}$ However, the uptake of isoflurane into blood via poly-(4-methyl-1-pentene) (PMP) oxygenators during CPB is severely limited. This should be taken into consideration in cases using such devices. ${ }^{80}$

But use of the VA as a sedative agent in ICU is limited for various technical reasons, especially administration, scavenging, occupational exposure and unfamiliarity of the staff about dosing and monitoring. The invention of AnaConDa (Sedana Medical, Uppsala, Sweden) and the new MIRUS system (Pall Medical, Dreieich, Germany) have made it possible to use VAs on ICU ventilators. To date, over 2300,000 AnaConDa's have been used in hospitals globally. The AnaConDa device is currently available with two different internal volumes, 100 and $50 \mathrm{~mL}$, each suiting patient over a different range of tidal volumes. (The $50 \mathrm{~mL}$ AnaConDa is suitable for use with tidal volumes as low as $200 \mathrm{~mL}$ ). ${ }^{81}$ In fact, the utilization of AnaConDa device is possible in children when placing it on the inspiratory ending. With three parameters: minute volume in liters (MV), sevoflurane concentration at the end of expiration (ETs) and weight in $\mathrm{kg}(\mathrm{Kg}), 84 \%$ of the variability of the sevoflurane flow (Fl) could be defined. ${ }^{82}$ Sackey et al placed the AnaConDa on the inspiratory limb before the Y-piece in paediatric patients, using it to simply deliver drug. ${ }^{83,84}$

Another important issue with use of VAs is associated environmental pollution. The global-warming potentials of isoflurane, sevoflurane, and desflurane (using $\mathrm{CO} 2$ as reference) are 1230,1980 , and 3714 , respectively. Although VAs contribute to the ozone layer-depleting factors with less than $0.03 \%$, the cumulative effect matters, given these compounds have a very long (4-21 years) elimination time. ${ }^{85,86}$ These agents have also been implicated in various animal and human studies, causing hepatotoxicity, renotoxicity, carcinogenesis, teratogenicity, mutagenesis, and infertility, but none has been proven conclusively. An impairment in cognitive and psychomotor function too has been reported, but when the exposure was held under the recommended level by applying appropriate protective measures, this too can be averted. However, a chronic exposure is assumed to affect the mental performance and central balance. ${ }^{87-90}$

Especially in the context of children, lie the concerns of neurotoxicity. But even the best-controlled studies have failed to demonstrate that anesthesia has a negative neurodevelopmental impact on infants, and an identification of dose, duration adjuvants that prevent or reduce the potential neurotoxicity of these agents is an area of active research. ${ }^{91,92}$

In a study by Picksworth, the mean concentration of the VA never reached more than $1 \mathrm{ppm} .{ }^{93}$ Similarly as shown by Marbini et $\mathrm{a}^{94}$ and Sackey et $\mathrm{al},{ }^{95}$ the mean concentration in 
the ambient air was well between 0.5 to $2 \mathrm{ppm}$. Although measured concentrations in atmosphere are below international exposure limits in most studies, further reduction of gas pollution must be of high priority. A minimum of 6 air changes per hour without recirculation to dilute VA adequately, the connection of a hose to the respirator's exhalation valve, from where gas is conducted to external air, the use of centrally controlled gas or vacuum based scavenging systems, and use of various adsorbers filled with charcoal. ${ }^{96}$

Also, the frequency of the patient's disconnection from the respirator should be restricted to minimum. A closed tracheal suctioning system is recommended. ${ }^{96}$

Fluoride toxicity is an area of concern with the use of VAs but various studies have pointed out that the rise in fluoride concentration is well below the toxic range (50 micromol) and the subtle parameters of the kidney function are within normal range. ${ }^{55,56}$

Animal studies suggest an important anti-inflammatory and immunomodulatory role of VAs. Sevoflurane has recently been shown to modulate the lung inflammatory response in a model of lung injury more favorably than propofol. Isoflurane and sevoflurane have been shown to impair the postischemic adhesion of PMNs in the intact coronary system of isolated reperfused guinea pig hearts and improved inflammatory response in one lung ventilation, cecal ligation and laparoscopic bariatric surgery. ${ }^{97}$ There are various reports of making use of VA sedation use in neurocritical care unit as well. ${ }^{98}$

\section{Limitations}

The biggest disadvantage in the pediatric ICU for the widespread applicability of the VAs as sedative is the potential deadspace created by the AnaConDa device itself and so increased work of breathing and $\mathrm{CO}_{2}$ retention. Hence, currently it cannot be used in neonates and small children requiring more than $200 \mathrm{~mL}$ of tidal volume. The staff also needs a proper training and protocol for proper handling of equipment and monitoring of the VA concentration in ICU. We have very limited and conflicting data on cost-effectiveness of VA application in ICU and more comprehensive analysis that includes wakeup time and extubation times is still awaited. They also require specialist medical licensing and government health approval for use in ICU. They are absolutely contraindicated in patients with malignant hyperthermia, although this condition is rare.

We have various IV agents that are in use in the ICU. These classes of drugs can be used synergistically but cannot replace each other, while our VAs are a complete analgesic and sedative agent. Apart from difficult to sedate patients with conventional drugs, a big reason for using volatiles in ICU has been the side effects of the IV agents, which are more pronounced in the pediatric age group, especially propofol infusion syndrome, hypertriglyridemia, delirium, tachyphylaxis and long-term neuropsychiatric disorders. ${ }^{44}$ The IV drugs have pharmacokinetic and pharmacodynamic variability in the pediatric age group. Also, oversedation that is an often associated problem is independently associated with posttraumatic stress syndrome and mortality. ${ }^{42}$ These agents also heavily rely on intact hepatic and renal function for drug metabolism and clearance, hence a problem of accumulation and toxicity is always there, as critically ill patients often have deranged hepatic and renal function. Infusion of these drugs require pumps, costly disposables and power, and associated with wastage of drugs as these have very short shelf life. Also, problem of excess volume infusion in the pediatric age group can never be overemphasized.

Even these are associated with considerable amount of water pollution directly due to extra drug being discarded and indirectly through human excretion. Use of IV drugs is associated with generation of considerable plastic waste; also, the persistence, bioaccumulation and toxicity (PBT) index of few drugs is considerably high, especially fentanyl and propofol. ${ }^{99}$ Safety of some drugs is still not established in neonates and their (propofol and dexmedetomidine) use in this age group is issued with a warning.

\section{Future Directions}

Xenon is a noble gas which has many desirable properties of that of an ideal analgesic and sedative agent. It has, in fact, been successfully used for sedation in a small group of patients who have undergone thoracic surgery without any adverse effects. ${ }^{100}$ Marking a further advancement, Sedana's AnaConDa device is in phase III trials for assessment of sedation in pediatric intensive care unit, and the invention of the emulsified isoflurane has opened up more avenues for regional anesthesia, organ protection, as well as anesthetic pharmacological study. ${ }^{101,102}$

The VAs have definitely expanded beyond the operating room, owing to various technological advancements as well as the safety profile of our ether anesthetics. The catharsis is not far when every ICU will be equipped serving VAs for sedation cause as Einstein said, "A theory is something nobody believes, except the person who made it. An experiment is something everybody believes, except the person who made it."

\section{Conflicts of Interest}

The authors declare no competing interests.

\section{References}

1 Chang AC. Pediatric cardiac intensive care: current state of the art and beyond the millennium. Curr Opin Pediatr 2000;12(3):238-246

2 Laussen PC. Neonates with congenital heart disease. Curr Opin Pediatr 2001;13(3):220-226

3 Chengode S, Menon PR. Anaesthesia for neonatal cardiac surgery. Ann Card Anaesth 2007;10(2):158-167

4 Lerman J, Jöhr M. Inhalational anesthesia vs total intravenous anesthesia (TIVA) for pediatric anesthesia. Paediatr Anaesth 2009;19(5):521-534

5 Baum VC, Yemen TA, Baum LD. Immediate 8\% sevoflurane induction in children: a comparison with incremental sevoflurane and incremental halothane. Anesth Analg 1997;85(2):313-316

6 Goa KL, Noble S, Spencer CM. Sevoflurane in paediatric anaesthesia: a review. Paediatr Drugs 1999;1(2):127-153

7 Vora KS, Shah VS, Patel D, Modi MP, Parikh GP. Sevoflurane versus propofol in the induction and maintenance of 
anaesthesia in children with laryngeal mask airway. Sri Lanka J Child Health 2014;43(2):77-83

8 Patel SS, Goa KL. Sevoflurane. A review of its pharmacodynamic and pharmacokinetic properties and its clinical use in general anaesthesia. Drugs 1996;51(4):658-700

9 Khan KS, Hayes I, Buggy DJ. Pharmacology of anaesthetic agents II: inhalation anaesthetic agents. Contin Educ Anaesth Crit Care Pain 2014;14(3):106-111

10 Mellor J. Induction of Anaesthesia in Paediatric Patient. Update in Anaesthesia. Available at: https://www.wfsahq. org/components/com_virtual_library/media/f64d7a4e7d8bda91d7675ff533728c3d-1790929530dd910afb692556af177 e82-Induction-of-Anaesthesia-in-Paediatric-Patient Accessed November 3, 2020

11 Awareness- Equipment Issues. Available at: https://www. openanesthesia.org/awareness-equipment-issues/ Accessed November 3, 2020

12 Philip JH, Hendrickx J. Importance of end-tidal agent monitoring as a standard of care. Anesthesia Patient Safety Foundation. Circulation 2019;34(2):45

13 Aranake A, Mashour GA, Avidan MS. Minimum alveolar concentration: ongoing relevance and clinical utility. Anaesthesia 2013;68(5):512-522

14 Stachnik J. Inhaled anesthetic agents. Am J Health Syst Pharm 2006;63(7):623-634

15 Cregg N, Wall C, Green D, Mannion D, Casey W. Humidification reduces coughing and breath-holding during inhalation induction with isoflurane in children. Can J Anaesth 1996;43(11):1090-1094

16 Boucher BA, Witt WO, Foster TS. The postoperative adverse effects of inhalational anesthetics. Heart Lung 1986;15(1):63-69

17 Porter LL, Blaauwendraad SM, Pieters BM. Respiratory and hemodynamic perioperative adverse events in intravenous versus inhalational induction in pediatric anesthesia: A systematic review and meta-analysis. Paediatr Anaesth 2020;30(8):859-866

18 Jerath A, Parotto M, Wasowicz M, Ferguson ND. Volatile anesthetics. is a new player emerging in critical care sedation? Am J Respir Crit Care Med 2016;193(11):1202-1212

19 Lerman J. Sevoflurane in pediatric anesthesia. Anesth Analg 1995;81(6(Suppl) L:S4-S10

20 Girotra S, Singh A, Mehta Y, Iyer KS, Trehan N. Comparison of sevoflurane and halothane for induction and intubation in pediatric cardiac surgical patients. Anesth Analg 1999;88SCA61 (abstract

21 Wodey E, Pladys P, Copin C, et al. Comparative hemodynamic depression of sevoflurane versus halothane in infants: an echocardiographic study. Anesthesiology 1997;87(4):795-800

22 Murray D, Vandewalker G, Matherne GP, Mahoney LT. Pulsed Doppler and two-dimensional echocardiography: comparison of halothane and isoflurane on cardiac function in infants and small children. Anesthesiology 1987;67(2):211-217

23 Murray DJ, Forbes RB, Mahoney LT. Comparative hemodynamic depression of halothane versus isoflurane in neonates and infants: an echocardiographic study. Anesth Analg 1992;74(3):329-337

24 Glenski JA, Friesen RH, Hassanein RS, Henry DB. Comparison of the hemodynamic and echocardiographic effects of sufentanil, fentanyl, isoflurane, and halothane for pediatric cardiovascular surgery. J Cardiothorac Anesth 1988;2(2):147-155

25 Rivenes SM, Lewin MB, Stayer SA, et al. Cardiovascular effects of sevoflurane, isoflurane, halothane, and fentanyl-midazolam in children with congenital heart disease: an echocardiographic study of myocardial contractility and hemodynamics. Anesthesiology 2001;94(2):223-229

26 Laird TH, Stayer SA, Rivenes SM, et al. Pulmonary-to-systemic blood flow ratio effects of sevoflurane, isoflurane, halothane, and fentanyl/midazolam with $100 \%$ oxygen in children with congenital heart disease. Anesth Analg 2002;95(5):1200-1206

27 Malhotra P, Mychaskiw G, Rai A. Desflurane versus opioid anesthesia for cardiac shunt procedures in infants with cyantoic congenital heart disease. Anesth Pain Med 2013;3(1):191-197

28 Ikemba CM, Su JT, Stayer SA, et al. Myocardial performance index with sevoflurane-pancuronium versus fentanyl-midazolam-pancuronium in infants with a functional single ventricle. Anesthesiology 2004;101(6):1298-1305

29 Symons JA, Myles PS. Myocardial protection with volatile anaesthetic agents during coronary artery bypass surgery: a meta-analysis. Br J Anaesth 2006;97(2):127-136

$30 \mathrm{Yu} \mathrm{CH}$, Beattie WS. The effects of volatile anesthetics on cardiac ischemic complications and mortality in CABG: a meta-analysis. Can J Anaesth 2006;53(9):906-918

31 Di Pumpo A, Candela C, Cucciniello F; et al. Volatile anesthetics in cardiac surgery: the impalpable benefit. Vessel Plus 2018;2:41

32 Landoni G, Augoustides JG, Guarracino F, et al. Mortality reduction in cardiac anesthesia and intensive care: results of the first International Consensus Conference. Acta Anaesthesiol Scand 2011;55(3):259-266

33 Riess ML, Kevin LG, Camara AK, Heisner JS, Stowe DF. Dual exposure to sevoflurane improves anesthetic preconditioning in intact hearts. Anesthesiology 2004;100(3):569-574

34 Beverstock J, Park T, Alston RP, Hutton S, Fathers J, Cawley W. A comparison of Volatile anesthesia and total intravenous anesthesia (TIVA) on outcome from cardiac surgery: a systematic review and metaanalysis. J Cardiothorac Vasc Anesth Published on 2020;(e-pub ahead of print). doi: 10.1053/j. jcva.2020.10.036

35 De Hert SG, Van der Linden PJ, Cromheecke S, et al. Cardioprotective properties of sevoflurane in patients undergoing coronary surgery with cardiopulmonary bypass are related to the modalities of its administration. Anesthesiology 2004;101(2):299-310

36 Jones BO, Pepe S, Sheeran FL, et al. Remote ischemic preconditioning in cyanosed neonates undergoing cardiopulmonary bypass: a randomized controlled trial. J Thorac Cardiovasc Surg 2013;146(6):1334-1340

37 Bettex DA, Wanner PM, Bosshart M, et al. Role of sevoflurane in organ protection during cardiac surgery in children: a randomized controlled trial. Interact Cardiovasc Thorac Surg 2015;20(2):157-165

38 Malagon I, Hogenbirk K, van Pelt J, Hazekamp MG, Bovill JG. Effect of three different anaesthetic agents on the postoperative production of cardiac troponin $\mathrm{T}$ in paediatric cardiac surgery. Br J Anaesth 2005;94(6):805-809

39 Singh P, Chauhan S, Jain G, Talwar S, Makhija N, Kiran U. Comparison of cardioprotective effects of volatile anesthetics in children undergoing ventricular septal defect closure. World J Pediatr Congenit Heart Surg 2013;4(1):24-29

40 Nigro Neto C, Landoni G, Cassarà L, De Simone F, Zangrillo A, Tardelli MA. Use of volatile anesthetics during cardiopulmonary bypass: a systematic review of adverse events. J Cardiothorac Vasc Anesth 2014;28(1):84-89

41 McMullan V, Alston RP, Tyrrell J. Volatile anaesthesia during cardiopulmonary bypass. Perfusion 2015;30(1):6-16

42 Hughes CG, McGrane S, Pandharipande PP. Sedation in the intensive care setting. Clin Pharmacol 2012;4:53-63

43 Vet NJ, Ista E, de Wildt SN, van Dijk M, Tibboel D, de Hoog M. Optimal sedation in pediatric intensive care patients: a systematic review. Intensive Care Med 2013;39(9):1524-1534

44 Rowe K, Fletcher S. Sedation in the intensive care unit. Contin Educ Anaesth Crit Care Pain 2008;8(2):50-55

45 Jabaudon $M$, Boucher $P$, Imhoff $E$, et al. Sevoflurane for sedation in acute respiratory distress syndrome. a 
randomized controlled pilot study. Am J Respir Crit Care Med 2017;195(6):792-800

46 Koutsogiannaki S, Shimaoka M, Yuki K. The use of volatile anesthetics as sedatives for acute respiratory distress syndrome. Transl Perioper Pain Med 2019;6(2):27-38

47 Bierman MI, Brown M, Muren O, Keenan RL, Glauser FL. Prolonged isoflurane anesthesia in status asthmaticus. Crit Care Med 1986;14(9):832-833

48 Kong KL, Willatts SM, Prys-Roberts C. Isoflurane compared with midazolam for sedation in the intensive care unit. BMJ 1989;298(6683) :1277-1280

49 Meiser $A$, Laubenthal $H$. Inhalational anaesthetics in the ICU: theory and practice of inhalational sedation in the ICU, economics, risk-benefit. Best Pract Res Clin Anaesthesiol 2005;19(3):523-538

50 Meiser A, Sirtl C, Bellgardt M, et al. Desflurane compared with propofol for postoperative sedation in the intensive care unit. Br J Anaesth 2003;90(3):273-280

51 Jerath A, Beattie SW, Chnady T, et al. Volatile- based short term sedation in cardiac surgical patients. Crit Care 2015;43(5):1062-1069

52 Hellström J, Öwall A, Sackey PV. Wake-up times following sedation with sevoflurane versus propofol after cardiac surgery. Scand Cardiovasc J 2012;46(5):262-268

53 Wascowicz M, van Rensurg A, Katznelson R, Jerath A, Djaiani G. Expanding an anesthesiologist role beyond an operating room. Volatile based sedation in cardiac surgical patients. Conference Paper. Br J Anaesth 2012;108(suppl 2):ii94, (abstract)

54 Röhm KD, Wolf MW, Schöllhorn T, Schellhaass A, Boldt J, Piper SN. Short-term sevoflurane sedation using the Anaesthetic Conserving Device after cardiothoracic surgery. Intensive Care Med 2008;34(9):1683-1689

55 Tanigami H, Yahagi N, Kumon K, et al. Long-term sedation with isoflurane in postoperative intensive care in cardiac surgery. Artif Organs 1997;21(1):21-23

56 Mesnil M, Capdevila X, Bringuier S, et al. Long-term sedation in intensive care unit: a randomized comparison between inhaled sevoflurane and intravenous propofol or midazolam. Intensive Care Med 2011;37(6):933-941

57 Kim HY, Lee JE, Kim HY, Kim J. Volatile sedation in the intensive care unit: A systematic review and meta-analysis. Medicine (Baltimore 2017;96(49):e8976

58 Spence J, Belley-Co^te', E, Ma, HK, et al. Efficacy and safety of inhaled anaesthetic for postoperative sedation during mechanical ventilation in adult cardiac surgery patients: a systematic review and meta-analysis. Br J Anaesth 2017;118(5):658-669

59 Jerath A, Panckhurst J, Parotto M, et al. Safety and efficacy of volatile anesthetic agents compared with standard intravenous midazolam/propofol sedation in ventilated critical care patients: a meta-analysis and systematic review of prospective trials. Anesth Analg 2017;124(4):1190-1199

60 Bellgardt M, Bomberg H, Herzog-Niescery J, et al. Survival after long-term isoflurane sedation as opposed to intravenous sedation in critically ill surgical patients: Retrospective analysis. Eur J Anaesthesiol 2016;33(1):6-13

61 Spencer EM, Willatts SM. Isoflurane for prolonged sedation in the intensive care unit; efficacy and safety. Intensive Care Med 1992;18(7):415-421

62 Palacios A, Mencía S, Llorente AM, et al. Sevoflurane therapy for severe refractory bronchospasm in children. Pediatr Crit Care Med 2016;17(8):e380-e384

63 Turner DA, Heitz D, Cooper MK, Smith PB, Arnold JH, Bateman ST. Isoflurane for life-threatening bronchospasm: a 15-year single-center experience. Respir Care 2012;57(11):1857-1864

64 Arnold JH, Truog RD, Rice SA. Prolonged administration of isoflurane to pediatric patients during mechanical ventilation. Anesth Analg 1993;76(3):520-526
65 Shankar V, Churchwell KB, Deshpande JK. Isoflurane therapy for severe refractory status asthmaticus in children. Intensive Care Med 2006;32(6):927-933

66 Carrié S, Anderson TA. Volatile anesthetics for status asthmaticus in pediatric patients: a comprehensive review and case series. Paediatr Anaesth 2015;25(5):460-467

67 Wheeler DS, Clapp CR, Ponaman ML, Bsn HM, Poss WB. Isoflurane therapy for status asthmaticus in children: a case series and protocol. Pediatr Crit Care Med 2000;1(1):55-59

68 Schutte D, Zwitserloot AM, Houmes R. de Hoog M, Draaisma JM, Lemson J. Sevoflurane therapy for life-threatening asthma in children. Br J Anaesth 2013;111(6):967-970

69 Curley MA, Molengraft JA. Providing comfort to critically ill pediatric patients: isoflurane. Crit Care Nurs Clin North Am 1995;7(2):267-274

70 Mirsattari SM, Sharpe MD, Young GB. Treatment of refractory status epilepticus with inhalational anesthetic agents isoflurane and desflurane. Arch Neurol 2004;61(8):1254-1259

71 yerra, A, Dr, F, Dr, D, Dr, L. Inhalational volatile anesthetic in surgery refractory status epilepticus- A case series from a tertiary care centre. Pediatr Crit Care Med 2018;19(6S):214

72 Mencía S, Palacios A, García M, et al. An exploratory study of sevoflurane as an alternative for difficult sedation in critically ill children. Pediatr Crit Care Med 2018;19(7):e335-e341

73 Jung C, Granados M, Marsol P, Murat I, Gall O. Use of sevoflurane sedation by the AnaConDa device as an adjunct to extubation in a pediatric burn patient. Burns 2008;34(1):136-138

74 Flinspach AN, Zacharowski K, Ioanna D, Adam EH. Volatile isoflurane in critically ill Coronavirus disease 2019 patients-A case series and systematic review. Crit Care Explor 2020;2(10):e0256

75 Nieuwenhuijs-Moeke GJ, Jainandunsing JS, Struys MM. Sevoflurane, a sigh of relief in COVID-19? $\mathrm{Br}$ J Anaesth 2020;125(2):118-121

76 Jerath A, Ferguson ND, Cuthbertson B. Inhalational volatile-based sedation for COVID-19 pneumonia and ARDS. Intensive Care Med 2020;46(8):1563-1566

77 Rand A, Zahn PK, Schildhauer TA, Waydhas C, Hamsen U. Inhalative sedation with small tidal volumes under venovenous ECMO. J Artif Organs 2018;21(2):201-205

78 Laufenberg $M$, Schneider T. [Severe exacerbation of COPD requiring ventilation : Use of vv-ECMO combined with inhalation anesthetics]. Med Klin Intensivmed Notf Med 2017;112(4):352-355

79 Meiser A, Bomberg H, Lepper PM, Trudzinski FC, Volk T, Groesdonk HV. Inhaled sedation in patients with acute respiratory distress syndrome undergoing extracorporeal membrane oxygenation. Anesth Analg 2017;125(4):1235-1239

80 Wiesenack C, Wiesner G, Keyl C, et al. In vivo uptake and elimination of isoflurane by different membrane oxygenators during cardiopulmonary bypass. Anesthesiology 2002;97(1):133-138

81 Farrell R, Oomen G, Carey P. A technical review of the history, development and performance of the anaesthetic conserving device "AnaConDa" for delivering volatile anaesthetic in intensive and post-operative critical care. J Clin Monit Comput 2018;32(4):595-604

82 Camaiora KA, Perez-Ferrer A, De Vicente Buendia J, Anillo Lombana VE, Gredilla E. Determination of a sevoflurane dosing formula for AnaConDa device in children. Eur J Anaesthesiol 2014;31:168

83 Sackey PV, Martling CR, Radell PJ. Three cases of PICU sedation with isoflurane delivered by the 'AnaConDa' Paediatr Anaesth 2005;15(10):879-885

84 Sackey PV, Martling CR, Granath F, Radell PJ. Prolonged isoflurane sedation of intensive care unit patients with the Anesthetic Conserving Device. Crit Care Med 2004;32(11):2241-2246 
85 Ryan SM, Nielsen CJ. Global warming potential of inhaled anesthetics: application to clinical use. Anesth Analg 2010;111(1):92-98

86 Langbein T, Sonntag H, Trapp D, et al. Volatile anaesthetics and the atmosphere: atmospheric lifetimes and atmospheric effects of halothane, enflurane, isoflurane, desflurane and sevoflurane. Br J Anaesth 1999;82(1):66-73

87 Kenna JG, Jones RM. The organ toxicity of inhaled anesthetics. Anesth Analg 1995;81(6(Suppl):S51-S66

88 Lucchini R, Belotti L, Cassitto MG, et al. Neurobehavioral functions in operating theatre personnel: a multicenter study. Med Lav 1997;88(5):396-405

89 Molina Aragonés JM, Ayora A, Barbara Ribalta A, et al. Occupational exposure to volatile anaesthetics: a systematic review. Occup Med (Lond 2016;66(3):202-207

90 Vouriot A, Gauchard GC, Chau N, Nadif R, Mur JM, Perrin PP. Chronic exposure to anesthetic gases affects balance control in operating room personnel. Neurotoxicology 2005;26(2):193-198

91 Thomas J, Crosby G, Drummond JC, Todd M. Anesthetic neurotoxicity: a difficult dragon to slay. Anesth Analg 2011;113(5):969-971

92 Bellinger DC, Calderon J. Neurotoxicity of general anesthetics in children: evidence and uncertainties. Curr Opin Pediatr 2019;31(2):267-273

93 Pickworth T, Jerath A, DeVine R, Kherani N, Wąsowicz M. The scavenging of volatile anesthetic agents in the cardiovascular intensive care unit environment: a technical report. Can J Anaesth 2013;60(1):38-43

94 Marbini HD, Palayiwa E, Chantler J. Active gas scavenging is unnecessary when using the AnaConDa volatile agent delivery system. Intensive Care Soc 2009;10:26-28
95 Sackey PV, Martling CR, Nise G, Radell PJ. Ambient isoflurane pollution and isoflurane consumption during intensive care unit sedation with the Anesthetic Conserving Device. Crit Care Med 2005;33(3):585-590

96 Soukup J, Schärff K, Kubosch K, Pohl C, Bomplitz M, Kompardt J. State of the art: sedation concepts with volatile anesthetics in critically Ill patients. J Crit Care 2009;24(4):535-544

97 Stollings LM, Jia LJ, Tang P, Dou H, Lu B, Xu Y. Immune Modulation by Volatile Anesthetics. Anesthesiology 2016;125(2):399-411

98 Villa F, Iacca C, Molinari AF, et al. Inhalation versus endovenous sedation in subarachnoid hemorrhage patients: effects on regional cerebral blood flow. Crit Care Med 2012;40(10):2797-2804

99 Axelrod D, Bell C, Feldman J et al. Greening the Operating Room. Greening the Operating Room and Perioperative arena: Environmental Sustainability for Anaesthesia Practice. Available at: https://www.asahq.org/about- asa/ governance-and-committees/asa-committees/committee-on-equipment- and-facilities/environmental-sustainability/greening-the-operating-room. Accessed December 16, 2020

100 Bedi A, Murray JM, Dingley J, Stevenson MA, Fee JP. Use of xenon as a sedative for patients receiving critical care. Crit Care Med 2003;31(10):2470-2477

101 Zhou C, Liu J. A novel intravenous general anestheticemulsified isoflurane: from bench to bedside. Front Med 2012;6(4):381-387

102 Landoni G, Lopez-Delgado JC, Sartini C, Tamà S, Zangrillo A. Halogenated agents and cardiovascular surgery: has mortality really decreased? Curr Vasc Pharmacol 2018;16(4):336-343, 477-480 